O funcionamento da ideologia no discurso separatista: uma análise de um texto vinculado ao movimento O Sul é o meu país | 171

\title{
O FUNCIONAMENTO DA IDEOLOGIA NO DISCURSO SEPARATISTA: UMA ANÁLISE DE UM TEXTO VINCULADO AO MOVIMENTO O SUL É O MEU PAÍS
}

\author{
Stella Aparecida Leite Lima ${ }^{65}$ \\ Luciana Iost Vinhas ${ }^{66}$
}

RESUMO: O presente artigo busca refletir, com base na Análise de Discurso com filiação a Michel Pêcheux, sobre os efeitos do discurso separatista colocados em circulação a partir do Movimento O Sul é Meu País. Tendo um texto vinculado ao Movimento como corpus, nos questionamos quais são os sentidos que podem ser colocados em circulação pelo Movimento. No texto analisado, encontramos expressões degradantes e designações que podem ser compreendidas através do funcionamento do excesso, conforme proposto por Ernst (2009). Nesse discurso, essas formulações promovem sentidos relacionados à violência, segundo nosso gesto interpretativo a partir do corpus estudado. Pensamos que os saberes desse discurso coexistem numa mesma região onde circulam saberes do Tradicionalismo gaúcho, portanto, junto a um imaginário que parece contribuir para a reprodução dos saberes separatistas.

Palavras-chave: O Sul é Meu País; Discurso separatista; Formação Discursiva; Análise do Discurso.

ABSTRACT: Based on the French Discourse Analysis proposed by Michel Pêcheux, this article aims to reflect on the effects of the separatist ideology put in circulation through the Movement O Sul é Meu Pais. Having one text as corpus of analysis, which was written by this Movement, we ask ourselves what the meanings that the Movement tries to put into circulation are. In the text we identified degrading expressions and designations that can be understood through the operation of the

\footnotetext{
${ }^{65}$ Professora de Língua Inglesa na Rede Particular no Estado de São Paulo. Mestre em Letras pela Universidade Católica de Pelotas.

${ }^{66}$ Professora de Língua Portuguesa e Linguística na UFPel. Membro dos grupos de pesquisa Laboratório de Estudos em Análise de Discurso (LEAD-UFPel), Grupo de Estudos Pêcheutianos (GEP-Unipampa) e Oficinas em Análise do Discurso: Conceitos em movimento (UFRGS). Doutora em Letras pela UFRGS.
} 
excess, as proposed by Ernst (2009). In that discourse, these formulations promote senses related to violence, according to our interpretive gesture based on the corpus. We believe that this discourse coexists in the same region of the gaucho traditionalism; therefore, it is next to an imaginary that seems to contribute to the reproduction of separatists discourses.

Keywords: O Sul é Meu País; Separatist Discourse; Discursive Formation; Discourse Analysis.

De acordo com a Análise de Discurso de base pêcheuxtiana, a ideologia é compreendida como evidência que se materializa em discurso, sendo a língua como uma das formas materiais da existência da ideologia. Tendo esses pressupostos fundamentais como base, podemos trabalhar com esse dispositivo teórico-analítico para analisar os processos discursivos decorrentes do imaginário separatista que se instaura no Sul do Brasil. Tal é o tema do trabalho que se desenvolverá a seguir.

A ideologia, assim como o inconsciente, tem um papel fundamental na constituição do sujeito. Em função dessa dupla determinação, o sujeito é levado a crer que sua autonomia é plena, que tem consciência de seus atos, pensamentos e do que fala. Isso porque, desde que se depara com o simbólico, o ser humano é chamado a interpretar o mundo, sendo a maneira como se identifica (ou não) com as evidências ligada diretamente à sua filiação discursiva. A ideologia, seguindo as palavras de Orlandi (1996, p. 66), "produz o efeito de evidência, sustentando-se sobre o já-dito, os sentidos institucionalizados, admitidos por todos como naturais".

Nosso objetivo é compreender o funcionamento ideológico do discurso colocado em circulação pelo Movimento O Sul é Meu País, tomando como base o texto intitulado "Uma resposta ao historiador Tau Golin" ${ }^{67}$, escrito por Celso Deucher, um dos representantes do Movimento. Entendemos a importância de se problematizar esse tema considerando as recentes transformações político-ideológicas ocorridas na formação social brasileira, atentando especialmente para possíveis traços de intolerância, derivados do fascismo, em determinadas práticas que estão se naturalizando em certos grupos organizados.

Para isso, é necessário apresentar brevemente o Movimento O Sul é Meu País, o qual teve seu primeiro registro oficial no ano de 1992,

${ }^{67} \mathrm{O}$ texto completo encontra-se no Anexo I. 
O funcionamento da ideologia no discurso separatista: uma análise de um texto vinculado ao movimento O Sul é o meu país | 173 durante o segundo Congresso Separatista, ocorrido na cidade de Laguna, em Santa Catarina (SC). Seu fundador foi Adílcio Cadorin, político do referido Estado. Atualmente, o grupo tem sede em Passo Fundo (RS), e é presidido por Odilon Xavier Freitas (diretoria 2014-2017). Celso Deucher, autor do texto que será analisado, é membro do Conselho Consultivo e já ocupou diversos cargos dentro do Movimento, inclusive o de Presidente, razão provável por ser um dos membros mais engajados e, portanto, estar presente em programas de rádio, TV e veículos de comunicação que têm interesse em dar visibilidade ao grupo.

Os habitantes da região Sul do Brasil, composta pelos estados do Rio Grande do Sul, Santa Catarina e Paraná, podem ser designados como sulinos, sulistas ou sul-brasileiros; seriam aqueles que, como escreve Ramil (2004, p. 07), "aparentam sentir-se os mais diferentes em um país feito de diferenças”. Em consequência, parece ser natural que esses brasileiros reconheçam sua diferença com os compatriotas de outras regiões devido a diferenças culturais, históricas e climáticas, elementos que os apartam das demais regiões do país. Essa relação de identificação pode ser concebida como um dos efeitos da imigração europeia, por uma proximidade maior com os países do extremo sul da América e considerável distanciamento geográfico do "centro" do País, além de possuírem costumes e tradições de séculos passados reproduzidas na contemporaneidade. Tal seria a explicação mais naturalizada para o fenômeno do imaginário de si como os mais diferentes em um país feito de diferenças. Essa visão, contudo, parte de uma posição tida como hegemônica, dominante, a qual desconsidera, por exemplo, o legado da população negra escravizada na região, tampouco das comunidades indígenas que nela habitavam. Podemos mencionar que as práticas e culturas oriundas da população africana e indígena instaladas nos três estados do sul do Brasil não se coadunam com o imaginário de sulista forjado sócio-historicamente. É importante referir, mesmo que de forma breve, que esse imaginário parte de uma posição dominante, posição da qual os representantes do Movimento O Sul É o Meu País enunciam.

No site do Movimento, é possível encontrar documentos em que são apresentados argumentos para subsidiar a proposta autodeterminista. Enunciados ${ }^{68}$ como: "o perfil (...) peculiar do sulino", "nossos ancestrais já

${ }^{68}$ Os enunciados foram retirados da Carta de Princípios do Movimento O Sul é Meu País e encontram-se disponíveis em: <http://www.sullivre.org/carta-deprincipios/>. Acesso em datas diversas. 
empunharam a bandeira da Independência e da Autonomia”, e, também, porque a região sul dispõe de "requisitos necessários para se tornar uma das nações mais prósperas do planeta” através do que eles chamam de "seu potencial humano" são exemplos da forma como o Movimento se autorrepresenta.

Ao mesmo tempo em que são considerados cidadãos brasileiros, aqueles que compõem o Movimento não se autorrepresentam como brasileiros, desejando a não identificação com essa imagem. Na esteira de Pêcheux (1997), mencionamos que é através da discursividade que os sujeitos põem em jogo suas relações imaginárias, ou seja, ao compreender a forma como os sujeitos se identificam com formações discursivas através da maneira como a ideologia os interpela - podemos atingir o funcionamento das formações imaginárias. A representação de si depende, portanto, do funcionamento das formações discursivas.

$O$ discurso da autodeterminação concebe a maneira pela qual os governantes poderão vir a decidir sobre todos os aspectos políticos e econômicos dos três estados, compondo, assim, um novo país a partir do descolamento da região sul do resto do Brasil. Dessa forma, observando o site www.sullivre.org ${ }^{69}$ encontramos um artigo que nos causou interesse por se tratar de uma resposta a uma matéria de cunho informativo sobre o Movimento.

Com base no que precede, então, propomo-nos a compreender os discursos colocados em circulação a partir da resposta dada por Celso Deucher, ativista do Movimento, a uma matéria veiculada pelo jornal Folha de São Paulo em 25 de julho de $2016^{70}$. A resposta foi publicada no site do Movimento no mesmo dia da publicação da matéria no jornal supracitado. Nosso corpus, então, concerne a um texto-resposta ${ }^{71}$.

É importante analisar os efeitos de sentido colocados em circulação a partir desse Movimento, considerando que seu objetivo é

\footnotetext{
${ }^{69}$ Endereço eletrônico do site do Movimento O Sul é Meu País.

${ }^{70}$ A matéria foi escrita pela jornalista Paula Sperb, do jornal A Folha de São Paulo, e tratou sobre o plebiscito consultivo que ocorreu em outubro do ano de 2016. Quem contribuiu com a matéria foi Anidria Rocha, representante do Movimento O Sul é Meu País (OSMP) no Rio Grande do Sul. O texto traz, também, além das informações de Anidria, opiniões de Tau Golin (historiador gaúcho), Davi Brasil (compositor gaúcho) e de Nairo Callegaro (presidente do Movimento Tradicionalista Gaúcho).

${ }^{71}$ Disponível em: <http://www.sullivre.org/uma-resposta-ao-historiador-tau-golin/ $>$ Acesso em datas diversas.
} 
O funcionamento da ideologia no discurso separatista: uma análise de um texto vinculado ao movimento O Sul é o meu país | 175 garantir a separação dos três estados do Sul do resto do país, constituindo uma nação diferente. Pretendemos compreender quais são as bases ideológicas do Movimento partindo da análise da carta-resposta escrita por Celso Deucher.

Justificamos a necessidade de realização do presente estudo em função da emergência crescente de movimentos separatistas, não só no Brasil como, também, em outros países. Nossa reflexão torna-se relevante pelo presente momento político, social e histórico pelo qual atravessamos. A crise na política, a corrupção, a economia e as dívidas dos Estados perante a União vêm garantindo um alarmante descontentamento à população brasileira. No caso dos sulistas, esse discurso se faz mais marcado, pois é sabido que o Estado do Rio Grande do Sul enfrenta uma grave crise interna, com parcelamento de salários dos servidores públicos, sucateamento da Educação pública estadual, tributos extras e altos índices de violência.

O estudo começa pela apresentação de algumas considerações referentes à Análise de Discurso (AD), a qual, segundo Orlandi (1994, p. 53) "se constitui na relação da Linguística com as Ciências Sociais". Entretanto, isso não quer dizer que a proposta de Pêcheux seja a de uma união entre disciplinas, pois ela se apresenta como mecanismo que trabalha a contradição presente em tais domínios. Contradição que é possível quando, na Linguística formal, a fala, o sujeito e sua exterioridade não são considerados, apagando a exterioridade, segundo a autora; já nas Ciências Sociais, é deixada de fora a propriedade de sistema significante que a linguagem apresenta, tratando-a como banco de sentidos.

Diante disso, a $\mathrm{AD}$ surge trazendo um objeto teórico singular, o discurso, através do qual observamos como se dá a relação entre linguagem e ideologia. Segundo Indursky (2010, p. 03),

Em seu primeiro texto, Pêcheux (1969), o fundador desse novo campo, afirma que discurso é efeito de sentido entre interlocutores. Ou seja, desde sua postulação inaugural, a exterioridade é convocada, sendo considerada como plenamente constitutiva do novo objeto. 
Pêcheux escreveu que é necessário contemplar a linguagem em seu funcionamento, pensá-la em relação à composição dos sujeitos e à produção de sentidos, ou, pelas palavras de Orlandi (1994, p. 53), ele nos instrui que "o discurso supõe um sistema significante, mas supõe também a relação deste sistema com sua exterioridade já que, sem história, não há sentido". Isso posto, pretendemos compreender "o que, pelo viés de um enunciado, se produz entre os locutores" (INDURSKY, 2011, p. 328).

Para o filósofo, o objetivo é de "estabelecer uma reflexão sobre sujeito e sobre funcionamentos linguístico-históricos" (MARIANI, 2003, p. 57); portanto, não interessam os locutores enquanto indivíduos empíricos, e, sim, suas posições, pois "o sujeito é o resultado da relação existente entre história e ideologia” (op. cit., p. 57). O que a autora refere acerca do sujeito da $\mathrm{AD}$ é que "a categoria de sujeito da Análise de Discurso deve considerar a causa [do que falha], na medida em que ela se "manifesta" incessantemente e sob mil formas" (p. 57). Isso significa que a discussão sobre subjetividade na teoria não passa longe da compreensão psicanalítica, compreendendo que a causa da falha suporta uma causa inconsciente. $\mathrm{O}$ sujeito que marca presença no quadro epistemológico da $\mathrm{AD}$ é concebido pelo viés da Psicanálise.

Dessa maneira, os sentidos são reproduzidos por sujeitos que, ao se inscreverem na língua, produzem história e, por serem constitutivamente incompletos e não-conscientes do processo de interpelação ideológica que os torna sujeitos, estão expostos a falhas, deslizes, equívocos. Em nosso trabalho, podemos mencionar que o fato de os sujeitos se posicionarem a favor ou contra a separação política da região sul do Brasil, por exemplo, revela a forma como eles se relacionam com a ideologia.

O processo de interpelação ideológica funciona através da injunção à identificação do sujeito com determinada formação discursiva. Desse modo, a maneira como o sujeito interpreta o mundo é efeito desse processo de identificação. A identificação possibilita a produção de sentidos a partir de determinada materialidade, sendo que nosso interesse se debruça sobre a materialidade linguística. Conforme Pêcheux (1988, p. 160),

as palavras, expressões, proposições, etc., mudam de sentido segundo as posições sustentadas por aqueles que as empregam, o que quer dizer que elas adquirem seu sentido em referência a essas posições, isto é, em 
O funcionamento da ideologia no discurso separatista: uma análise de um texto vinculado ao movimento O Sul é o meu país | 177 referência às formações ideológicas (...) nas quais essas posições se inscrevem. Chamaremos, então, formação discursiva aquilo que, numa formação ideológica dada, isto é, a partir de uma posição dada numa conjuntura dada, determinada pelo estado da luta de classes, determina o que pode e deve ser dito (articulado sob a forma de uma arenga, de um sermão, de um panfleto, de uma exposição, de um programa, etc.).

As formações discursivas são compreendidas como "regiões" do interdiscurso, com as quais o sujeito se relaciona no processo de interpelação ideológica. Os sentidos não existem, portanto, em uma relação literal com as palavras, pois, na verdade, o sentido é estabelecido a partir da inscrição de determinada palavra, expressão ou proposição em uma formação discursiva. Com base nisso, podemos dizer que diferentes efeitos de sentido podem ser colocados em circulação a partir do texto que será aqui analisado. Podemos explicar tal situação de uma forma superficial: caso exista uma identificação do sujeito que interpreta com a formação discursiva separatista, existirá, então, um processo de identificação do sujeito com os saberes colocados em circulação pelo texto; no entanto, se ocorrer o processo contrário, ou seja, se não existir identificação do sujeito com a formação discursiva separatista, é possível que os saberes colocados em circulação a partir do texto sejam negados, questionados, pelo sujeito interpretante.

Ainda pensando no texto analisado, como primeira reflexão, em seu título encontramos a designação "resposta" precedida pelo artigo indefinido "uma", indicando a indeterminação do sintagma nominal, o que nos possibilita compreender que a resposta não será qualquer, e, também, que ela pode ser "uma” entre muitas possíveis. Todavia, o artigo traz, em seu título, o nome de Tau Golin, determinando a quem a resposta está direcionada.

Por meio de uma busca bibliográfica virtual ${ }^{72}$ verificamos que o historiador, professor e pesquisador Tau Golin tem um currículo bastante diversificado, e coordena projetos de estudos culturais e arqueológicos do

${ }^{72}$ Lattes CNPQ <http://lattes.cnpq.br>, $<$ http://lattes.cnpq.br/3147241105057327> Acesso em 20.01.2017. 
Sul do Brasil. Ele também é escritor e tem, entre suas obras, "História Geral do Rio Grande do Sul", "A Fronteira" e "O Povo do Pampa". Ele atua no Sul, pesquisa sobre o Sul, escreve sobre o Sul, é gaúcho, e, portanto, Sulista. Por que, então, haveria uma "resposta", por parte do OSMP, a ele e tal resposta seria em sentido de concordância ou discordância?

Importante mencionar que Golin também é autor do livro "A ideologia do Gauchismo", obra de 1983 que discorre sobre a origem do Tradicionalismo do RS utilizando registros dos próprios representantes culturais do Estado, mídia impressa etc., e que reflete sobre como se deu a idealização do gaúcho. Contudo, os escritos de Golin vão de encontro à crença alimentada durante anos na cultura rio-grandense, que, segundo o autor, é "uma cultura "popular" - produzida hegemonicamente pela elite - voltada para o seu espaço geográfico e social” (GOLIN, 1983, p. 11), na qual "exploradores e explorados defendem os mesmos princípios na compreensão de mundo" (op. cit., p. 12).

Logo, uma vez que se compreenda como o historiador reproduz saberes sobre a história da região Sul, como ele se relaciona com aquilo que se naturalizou historicamente sobre o gaúcho, podemos compreender que há sentidos em disputa sobre o sulismo. Tau Golin mostra-se contrário ao ordinário proposto pelo "Partenon Literário" (GOLIN, 1983 , p. 11), às "estórias" contadas popularmente, ou seja, às relações de causalidade a partir das quais derivaram os sentidos tradicionalistas atribuídos ao gaúcho/sulista. Petri (2004, p. 17), ao estudar a literatura gaúcha como materialidade discursiva, escreve que, "no caso desse discurso, a interlocução recupera elementos advindos do mundo social, representados pela história e recontados na ficção, onde se produzem efeitos de sentido capazes de contribuir para a instituição de um mito ou para a desmitificação de um herói".

Ao mesmo tempo, com os jornais, a TV, o rádio e a internet, podemos intuir que sentidos tradicionalistas emergem do texto de Deucher e são, na atualidade, reproduzidos midiaticamente, podendo ser vistos em programas televisivos como Galpão Crioulo ${ }^{73}$, em rádios como a Nativa FM $^{74}$ e nas festividades da Semana Farroupilha, não apenas com a cobertura da mídia, mas, também, nas instituições que atuam como um

\footnotetext{
${ }^{73}$ Programa da RBS TV - afiliada da Rede Globo no Rio Grande do Sul - exibido todos os domingos.

${ }^{74}$ Rádio de Piratini-RS - 〈http://www.nativafmpiratini.com.br/>. Acesso em $14 / 02 / 2017$.
} 
O funcionamento da ideologia no discurso separatista: uma análise de um texto vinculado ao movimento O Sul é o meu país | 179 meio para a reprodução desses saberes. Um exemplo pode ser visto no Instituto Estadual Professor Osmar Poppe, da cidade São Luiz Gonzaga, onde, durante a Semana Farroupilha,

os alunos deixa(ra)m de lado o tradicional
uniforme ou a combinação de jeans e
camiseta, para usar vestidos de prenda ou
bombachas (...) de segunda à sexta-feira, em
todos os turnos, os alunos realiza(r)am
atividades especiais (...) palestras,
apresentações de danças típicas gaúchas,
concurso interno de prendas e peões,
gincana cultural e futebol de bombacha.
Cada turma montou seus piquetes no pátio
interno e externo da escola ${ }^{75}$.

Sendo assim, consideramos que os saberes marcados pelo texto analisado vão de encontro à posição discursiva de Tau Golin presente na matéria referida, que entende tal aparato cultural "como não distanciado da luta de classes" (GOLIN, 1983, p. 11). Esse entendimento se dá em razão de que, desde quando o Tradicionalismo foi pensado e reproduzido, até seu fortalecimento, "sua ideologia constituía-se fundamentalmente latifundiária” (op. cit., p. 11). Com isso, podemos pensar que, da "resposta" endereçada a Tau Golin pelo OSMP emergem efeitos de sentido referentes a saberes contrários ao que o historiador reproduz.

Antes de seguir, porém, é pertinente esclarecer que acreditamos que a materialidade sob análise proporciona vários elementos importantes para debate; no entanto, nesse estudo, nos concentraremos no excesso de emprego de pronomes, designações e expressões presentes no corpus e consideradas semanticamente negativas. Além disso, em nossa análise, não trataremos dos sujeitos Tau Golin e Celso Deucher como sujeitos empíricos, e, sim, das posições discursivas que reproduzem como sujeitos enunciadores.

Essas posições se dão em relação às formações discursivas, que, por sua vez, provêm de suas relações sociais, em funcionamento no

\footnotetext{
${ }^{75}$ Retirado do website <https://social.shorthand.com/Amandaaafox/j260WmVwgf/escolas-mantemviva-a-tradicao-gaucha>. Acesso em 14/02/2017.
} 
discurso reproduzido a partir desses textos. Daqui para frente, tais posições aparecerão como posição pró OSMP e posição contra OSMP. O ponto interessante que pode ser colocado em circulação a partir da Análise de Discurso é que essas posições não podem ser consideradas como excludentes, porque é nas suas contradições que acontecem as suas determinações. Isso significa que um determinado discurso se constitui pelo discurso-outro, mesmo sendo eles antagônicos.

Essas posições podem ser identificadas, em nosso entendimento, no uso da materialidade linguística dos pronomes "nós" e "nos", do adjetivo possessivo "nosso" e dos verbos em primeira pessoa do plural empregados com elipse do sujeito. De acordo com o que propõe Ernst (2009, p. 04) sobre o excesso, entendemos que a presença desses significantes "constitue(m)-se em um "acréscimo necessário" ao sujeito que visa garantir a estabilização de determinados efeitos de sentido em vista da iminência (e perigo) de outros a esses se sobreporem". Vejamos os possíveis funcionamentos, nas SDs presentes no texto ${ }^{76}$ :

SD11. Como todo historiador, pena alugada de Brasília, Golin odeia negros e índios, por isso não aceita nossa anterioridade missioneira, muito menos que entre nós estejam lutando lado a lado cidadãos de origem africana que vencem na vida pelas suas capacidades e não pelas cotas discriminadoras impostas pelo poder central. SD14. Nós os separatistas, repudiamos com veemência tais argumentos, ideias e ideologias. O Sr. Golin não tem o direito de tratar nossa gente desta forma.

SD21. Nós os independentistas continuamos a espera de argumentos que derrubem nossas teses. [grifos nossos]

Nessas formulações, compreendemos poder se tratar de um "elemento não apenas linguístico" (CAZARIN, 2004, p. 188), pois o "nós" tem, com frequência, o papel de um "locutor coletivo" (op. cit. p. 188). Segundo Benveniste (1995), a partir da perspectiva da Teoria da

\footnotetext{
76 As sequências discursivas de referência (SDs) recortadas do texto analisado encontram-se no Anexo I.
} 
O funcionamento da ideologia no discurso separatista: uma análise de um texto vinculado ao movimento O Sul é o meu país $\mid 181$ Enunciação, o "nós" se configura como uma pessoa ampliada, o eu (subjetivo) acrescido de alguém que toma a palavra, mas estende essa voz a outros, fazendo com que o referente seja composto por outros sujeitos definidos por esse "eu" ampliado.

Nesse sentido, entendemos que o "nós" não instaura uma indeterminação referencial como escreveu Geffroy (1985 apud CAZARIN, 2004) ao tratar de seu uso. Para a autora, "essa é uma forma pronominal rica em potencialidades dialógicas e a análise de seu funcionamento discursivo coloca duas questões centrais: Quais pessoas o "nós" convoca para si e por quê?" (op. cit., p. 188).

Assim, ao usar o "nós" nas SD14 e SD21, o texto determina seu referente discursivo, ou seja, quem seria esse "nós": como ele pode ser significado a partir da formação discursiva com a qual se identifica o sujeito-enunciador que coloca os seus saberes em circulação. Nos estudos em $\mathrm{AD}$, o funcionamento discursivo do "nós" pode ser concebido como político, conforme Indursky (2000, p. 23): "enunciar em "nós" de forma inclusiva é a melhor maneira de representação do sujeito político, na medida em que elege a si e a seus representados (...) como aqueles que constituem a referência desse "nós"”.

Ainda segundo a autora, esse funcionamento abrange um "nós" ampliado que representa diferentes segmentos sociais inscritos na posição discursiva a partir da qual o sujeito enuncia. Os substantivos utilizados pelo sujeito enunciador (eu), ao concordarem em número (ampliado) com o sujeito (nós) a que se referem, através do morfema de flexão (-mos) dos verbos "repudiamos/continuamos" que foram destacados, sugerem o "eu mais alguém" também identificado com a posição separatista; bem como o artigo definido "os", que, por sua vez, antecedendo "separatistas/independentistas", qualifica o "nós" nas formulações.

Nessa linha de pensamento, os substantivos "separatistas" e "independentistas" atuam na mesma rede parafrástica para designar os sujeitos que se filiam aos saberes separatistas, indicando uma formulação diferente "do mesmo dizer sedimentado" que representa o "retorno ao mesmo espaço de dizer" (ORLANDI, 2009, p. 36), remetendo-os ao mesmo referente.

Segundo Geffroy (1985 apud CAZARIN, 2004, p. 188), "a riqueza das potencialidades enunciativas do "nós" só pode ser definida por sua exterioridade", ou seja, "para que se possa designar a referência ou autorreferência do "nós", é necessário levar em conta os laços sociais, a constituição do sujeito falante em sujeito do discurso, enfim, a ideologia". 
Portanto, é possível compreendermos que o sujeito do discurso separatista (sul-brasileiro) é interpelado ideologicamente de modo a reproduzir saberes de região do interdiscurso que fazem emergir sentidos já estabelecidos, colocando em circulação saberes de ordem separatista.

Ao mesmo tempo em que funciona de maneira inclusiva, o significante pronominal funciona de modo a promover as relações de força, ou seja, ao "excluir" aqueles que são Sulistas, mas não separatistas, o "nós" se torna exclusivo aos sujeitos que reproduzem tal discurso e se filiam aos saberes que estão em circulação no texto analisado. Isso nos possibilita entender que nem todos os sujeitos identificados com os saberes tradicionalistas da região Sul se identificam com os saberes separatistas, mesmo que esses saberes lhes estejam disponíveis de forma hegemônica.

Percebemos outra particularidade do funcionamento discursivo do "nós": a indeterminação. Se, nas sequências SD14 e SD21, o sujeito pró OSMP separa os sulistas entre separatistas e não-separatistas, nas formulações a seguir observarmos outro funcionamento através de pronomes adjetivos.

SD01. Como todo historiador, pena alugada de Brasília, Golin odeia negros e índios, por isso não aceita nossa anterioridade missioneira (...).

SD15. Somos Povo e Nação cuja unidade vem sendo forjada pela nossa diversidade e ninguém vai nos destituir do nosso irrenunciável direito de sermos sujeitos do direito de autodeterminação.

SD14. (...) O Sr. Golin não tem o direito de tratar nossa gente desta forma.

SD19. Pelos motivos apontados acima, Tau Golin, cego pela sua ideologia, não conseguiu argumentos honestos para combater o independentismo Sulista, que nada mais quer que refazer o papel do estado em nossa região.

SD21. (...) argumentos que derrubem nossas teses.

SD09. voltaram para nossas cidades e estados, depois de quase implorarmos, a 
O funcionamento da ideologia no discurso separatista: uma análise de um texto vinculado ao movimento O Sul é o meu país | 183 miséria de $\mathrm{R} \$ 153.320 .315 .743,00$. [grifos nossos]

Podemos inferir que o texto inclui os sujeitos não identificados com os saberes separatistas ao empregar os adjuntos adnominais em "nossa anterioridade missioneira" (SD11), "nossa diversidade" (SD15), "nossa gente" (SD14), "nossa região" (SD19) e "nossas cidades e estados" (SD9), pois remetem a saberes não-exclusivos aos separatistas, ou seja, os saberes tradicionalistas disponíveis no interdiscurso subsidiam sentidos da formação discursiva separatista, na qual figura uma posição-sujeito separatista-sul-brasileira; com tais formulações, falar-se-ia do lugar de todos sujeitos sulistas, sejam eles identificados ou não aos saberes separatistas.

Isso nos faz refletir que o funcionamento do emprego dos pronomes "visa garantir a estabilização de determinados efeitos de sentido em vista da iminência (e perigo) de outros a esses se sobreporem" (ERNST, 2009, p. 04), ou seja, quando o sujeito põe em curso os saberes que permeiam um "imaginário coletivo", não faz distinção entre os sujeitos que podem se identificar com os saberes separatistas ou não. $\mathrm{O}$ excesso identificado no eixo do intradiscurso atua no sentido de manter a estabilidade do discurso.

Em vista disso, "a interpelação ideológica fornece a cada sujeito sua "realidade" enquanto sistema de evidências e de significações percebidas" (ORLANDI, 2010, p. 18), quando, a partir de sua inclusão na ordem significante, os sujeitos vão se identificando com saberes colocados em circulação, sentidos vinculados a formações discursivas, que podem, por consequência, ser de formações antagônicas.

No caso do texto de Celso Deucher reportando à intervenção de Tau Golin presente na matéria da Folha de S. Paulo, percebemos que circulam saberes sulistas, tradicionalistas e, também, que o separatismo, em cada um deles, aparece representado por saberes derivados de regiões diferentes. Isso porque, em cada materialidade, o separatismo recebe definições opostas, sejam elas, "um movimento antibrasileiro" (Tau Golin) ou "um fenômeno social" (Celso Deucher), sendo possível, portanto, pensar se tratar de posições discursivas materializadas a partir de formações discursivas antagônicas.

Observamos os efeitos de sentido que emergem em dadas posições através, por um lado, do sintagma "anterioridade missioneira" recortado da SD1 do texto de Deucher, e, por outro lado, da sequência "dificuldade 
(...) de se integrar à nação ${ }^{77 "}$ presente na fala de Tau Golin. Em nossa leitura, essas formulações seriam decorrentes da forma como o separatismo é representado a partir das diferentes formações discursivas.

Dessa maneira, quando, no texto analisado, temos "esquece criminosamente Golin das origens do separatismo Sulista", entendemos que a posição discursiva pró OSMP, ou o lugar imaginário separatista, tem uma densa ligação com o passado e o Tradicionalismo (gaúcho), de modo a manter ativa a memória "de um povo (...) que se sentia explorado pelo colonizador estrangeiro" (PETRI, 2004, p. 101), projetando as "imagens de sujeito que construíram a história do sul do Brasil e que mais tarde são idealizadas pela classe artística que eleva um sujeito imaginário ao estatuto de herói regional" (op. cit. p. 23), reforçando o senso comum do ser "reconhecido dentro e fora das fronteiras do Rio Grande do Sul (aqui, região Sul), por sua bravura e destemor" (op. cit., p. 24).

Em Análise de Discurso, o imaginário se institui como um efeito do atravessamento da ideologia. O sujeito se constitui, então, afetado pelo simbólico (inconsciente) e pela ideologia. Como consequência dos saberes oriundos do interdiscurso e organizados por "regiões" (FDs), os textos reproduzem sentidos que determinam suas filiações, como podemos observar no texto de Celso Deucher, quando são evocados sentidos a partir da história, que constituem o imaginário sobre o separatismo Sulista:

SD10. Como "historiador", esquece criminosamente Golin das origens do separatismo Sulista, que teve seu primeiro embate nas Missões do Guairá, seguiu o curso da história nos Sete Povos das Missões, mais tarde na Revolução Farroupilha, na Revolução Federalista, na Guerra do Contestado e em tantas outras revoluções gestadas no Sul. Em sua esmagadora maioria, revoluções que nasceram para lutar contra a falta de auto-governo dos Sulistas.

77 O excerto foi recortado a partir da fala de Tau Golin na matéria da Folha de São Paulo: "É um movimento antibrasileiro que mostra a dificuldade que certos grupos têm de se integrar à nação”. 
O funcionamento da ideologia no discurso separatista: uma análise de um texto vinculado ao movimento O Sul é o meu país | 185

Logo, no caso do referido texto, consideramos que saberes do interdiscurso estão organizados em uma formação discursiva a favor do separatismo, ou seja, uma FD Separatista, fluida, porosa, sem limites. Na referida FD estão abrigados saberes de ordem separatista, sendo que, no presente trabalho, estamos analisando especificamente o separatismo da região sul do Brasil, com base no Movimento que quer formar um país à parte.

Com isso, podemos compreender que a forma como o Movimento O Sul é Meu País se relaciona com a ideologia é determinada por uma formação discursiva que envolve sentidos motivados pelo Tradicionalismo e pelo separatismo (pela intolerância ao diferente), o que, por sua vez, pode materializar sequências como a SD15 “(...) irrenunciável direito de sermos sujeitos do direito de autodeterminação”, ou a SD10 “(...) a falta de auto-governo dos Sulistas”, já que a reprodução de aspectos favoráveis à autodeterminação remete a sentidos produzidos e reproduzidos discursivamente durante séculos na região. $O$ desejo separatista está recalcado há muito tempo na região sul do Brasil, conforme observamos na SD10.

Por outro lado, a partir da FD Separatista destacada, são estabelecidas relações de antagonismo a partir do lugar no qual se inscreve a oposição ao Movimento. Ao invés de serem considerados como elementos de caráter positivo para a região sul do país, podemos dizer que os saberes que trabalham antagonicamente aos saberes separatistas consideram o separatismo como "um elemento na Superestrutura (...) correlacionado com todos os outros organismos de sustentação da classe dominante" (GOLIN, 1983, p.13), pois é fruto de estratégias dos grupos dominantes para a consolidação e perpetuação de seu domínio. Pode-se dizer, então, que o separatismo ganha um caráter semanticamente negativo, pois estaria operando no processo de reprodução das relações de dominação e exploração promovidas pela classe dominante.

Segundo o autor, a ideologia Tradicionalista tem o papel importante de "fazer persistir ideias correspondentes a um tempo histórico pretérito, claramente delimitado e falseado historicamente, numa outra estrutura social" (op. cit., p. 12) e que, em nosso entendimento, atuam como elementos que alimentam a reprodução dos saberes inscritos na FD separatista, materializada a partir do texto de Celso Deucher em resposta à manifestação de Tau Golin.

Assim, Tau Golin coloca em circulação sentidos contrários aos da FD Separatista, como podemos perceber através da formulação "os 
separatistas (...) não admitem a ideia de pluralidade”. Uma FD antagônica na qual os mitos são compreendidos enquanto processo de dominação ideológica, contrária a "uma visão positivista que defende a exaltação (...) ocultando suas fraquezas e aspectos negativos" (GOLIN, 1983, p. 14).

Durante o exercício analítico, causou-nos estranhamento ${ }^{78}$ a presença das sequências a seguir no texto analisado: "as afirmações xenofóbicas do Professor" (SD16) e "coloca-se ao lado do malfadado Mussolini” (SD17). Podemos, então, tecer elementos para constituir uma rede de sentidos sobre xenofobia, conforme segue.

No dicionário Michaelis online, xenofobia é definida como "aversão ou rejeição a pessoas ou coisas estrangeiras" ou como "temor ou antipatia pelo que é incomum ou estranho ao seu ambiente"79. A xenofobia seria atribuída a alguém que sente uma ameaça de um estranho externo que vem descaracterizar uma unidade constituída. Deucher estaria atribuindo essa característica a Golin, pois, segundo o primeiro, "Somos Povo e Nação cuja unidade vem sendo forjada pela nossa diversidade" (SD15). Portanto, a representação da posição de Deucher revela a existência uma unidade sulista baseada na diversidade. Supostamente, segundo Deucher, Golin se afastaria dessa concepção, pois considera que suas afirmações são xenofóbicas. Estranho nos parece esse comentário, já que é Deucher quem está defendendo o separatismo sulista.

Sendo assim, apesar de Deucher trazer o significante "diversidade" em seu texto, a diversidade é considerada como produtora de unidade. Ou seja, no interior da FD Separatista circulam saberes que suscitam o sentido de um "Povo e Nação cuja unidade vem sendo forjada pela (nossa) diversidade”, em função de os Sulistas serem diferentes dos demais brasileiros e não por disporem de qualidades e características variadas assim como o restante da população.

Outro vestígio linguístico que corrobora com tal compreensão está na formulação "a cultura rio-grandense (...) deveria ser simplesmente deletada para dar lugar certamente a cultura Cubana”, a partir da qual podemos entender uma crítica à forma como Tau Golin se posiciona ideologicamente, promovendo o entendimento de que a cultura cubana não seria digna de respeito e cortesia. Surgem, novamente, elementos que

\footnotetext{
${ }^{78}$ Nossa compreensão de estranhamento vem de Ernst (2009).

${ }^{79}$ Disponível em:

$\langle$ http: $/ /$ michaelis.uol.com.br/busca? $\mathrm{r}=0 \& \mathrm{f}=0 \& \mathrm{t}=0$ \& palavra $=$ xenofobia $>$. Acesso em 26 de fevereiro de 2017.
} 
O funcionamento da ideologia no discurso separatista: uma análise de um texto vinculado ao movimento O Sul é o meu país | 187 apontam para a unidade em relação de intolerância com aquilo que está fora dessa unidade.

Tau Golin, por sua vez, diz que “os separatistas não admitem a ideia de pluralidade e consideram descendentes de italianos e alemães, comuns no Sul, como especiais ou raça superior"'. Nesse sentido, a "diversidade" a que faz referência Deucher não daria conta da diversidade étnico-racial que constitui os três estados da região sul do país, pois a representação que o Movimento possui de sulista está fortemente vinculada à imagem do povo europeu que passou a colonizar a região e, gradativamente, a dominar os meios de produção. Negros e índios, por exemplo, não fazem parte da representação de diversidade a partir da qual o discurso é colocado em circulação.

Nossa reflexão caminha na direção de se compreender o discurso Separatista como representante da intolerância: a identidade Sulista não permite que essa identidade seja afetada pela identidade Brasileira, na qual estariam incluídos outros tipos de determinação via ideologia e cultura. A unidade sulista deve, então, ser mantida através do rompimento político com o resto da Federação. Para seguir nessa direção, trazemos, primeiramente, uma citação de Arendt (1989, p. 26-27),

uma ideologia que tem de persuadir e mobilizar as massas não pode escolher sua vítima arbitrariamente. Em outras palavras, se o número de pessoas que acreditam na veracidade de uma fraude tão evidente (...) é bastante elevado para dar a essa fraude o foro do dogma de todo um movimento político, a tarefa do historiador já não consiste em descobrir a fraude, pois o fato de tantos acreditarem nela é mais importante do que a circunstância de se tratar de uma fraude.

Podemos relacionar a ideologia de dominação das massas da qual trata Arendt (1989) e a "combinação de valores conservadores, técnicas de democracia de massa e a inovadora ideologia (...) irracionalista centrada em essência no nacionalismo" (HOBSBAWM, 1995, p. 122) aos saberes colocados em circulação a partir do texto analisado, por tentar "manter um efeito imaginário produzido pela ideologia” (PETRI, 2004, p. 53) quando diz que "o bom historiador busca na anterioridade histórica os 
motivos que levam milhões de pessoas a acreditar que a independência de um determinado território é melhor que ficar a mercê de um estado central capenga, patrimonialista e pior que isso, neocolonista" (SD07).

A formulação também nos remete aos "movimentos de unificação" que tinham o objetivo de destruir o Estado (ARENDT, 1989); portanto, parece-nos contraditório que tanto o texto de Deucher quanto o texto de Golin façam referência à xenofobia, um exercício discriminatório que abrange uma carga semântica remanescente do fascismo, como podemos ler em Arendt (1989) e em Hobsbawm (1995).

Quando Hobsbawm (1995) discorre sobre a ascensão fascista no século XIX, escreve que, durante aquele período histórico, "homens e mulheres migravam não apenas para o outro lado de oceanos e fronteiras internacionais, mas do campo para a cidade; de uma região do mesmo país para outra" (HOBSBAW, 1995, p. 122). Segundo o autor, essa imigração foi o que "introduziu a xenofobia de massa" na qual a intolerância ao diferente "tornou-se a expressão comum" (op. cit., p. 122).

Tau Golin afirma, na reportagem já mencionada, que alguns grupos possuem dificuldade de se integrar à nação. Compreendemos que o imaginário sulista tradicionalista e, por consequência, separatista, reproduz sentidos de intolerância. Isso provavelmente se dá em razão da incapacidade de respeitar, de praticar a alteridade através do diálogo (CASARA, 2015).

O autor ainda escreve como se dão as relações quando imersas na ideologia autoritarista do fascismo e, com isso, podemos observar que, entre a memória e as definições que compõem a historicidade do significante fascismo, encontra-se o que há de marcante no regime utilizado por Mussolini e outros. Ele destaca que "no fascismo, há uma tentativa de edificação de um Estado total, isto é, um Estado que se sobreponha ao indivíduo a ponto de anulá-lo. Não por acaso, a intolerância torna-se uma constante, o que leva à repressão da diferença" (CASARA, 2015, p. 13).

Nossa compreensão de fascismo no presente texto vem de Orlandi e Vinhas (2017, p. 09). As autoras mencionam que

O fascismo é aqui pensado a partir de duas perspectivas: a primeira referente a regimes totalitários vinculados a uma classe colonizadora, dominante e ressentida (tais como o nazismo alemão e as ditaduras latinoamericanas) e a segunda, atrelada a exercícios 
O funcionamento da ideologia no discurso separatista: uma análise de um texto vinculado ao movimento O Sul é o meu país | 189 cotidianos e assimétricos de poder, marcados pela imposição de modos de vida, saberes e fazeres fascistas (KOHAN, 2009). O fascismo pauta-se na diferenciação hierárquica e excludente do(a) outro(a), o(a) qual é categorizado(a) em termos de utilidade ou inadequação, sendo intoleráveis todo(a)s aquele(a)s distinto(a)s da normatividade. Tal processo colonizador fundamenta-se na legitimação de um "povo" idealizado e apegado a seus privilégios. Aos privilegiados não parece estranho naturalizar, aceitar, acostumar e compactuar com todo tipo de desigualdade, seja a pobreza, a misoginia, o racismo, a GLBTIfobia ou toda e qualquer forma de rejeição de alteridade.

Sendo assim, manifestações de intolerância àquilo que se afasta da normatividade podem se caracterizar como fascismo. Encontramos, no texto analisado, uma formulação que parece reproduzir essa inscrição ideológica: “(...) o independentismo Sulista, (...) nada mais quer que refazer o papel do estado em nossa região" (SD19). Voltamos a Arendt (1989, p. 290), pois parece significar "que naturalmente governaria em proveito de sua própria classe (aqui, região) e em detrimento de todas as outras".

Por isso, compreendemos que as sequências "as afirmações xenofóbicas do Professor" e "coloca-se ao lado do malfadado Mussolini", já anteriormente referidas, podem remeter ao discurso autoritário/fascista, ou seja, à sobreposição do Estado ao sujeito, garantida pela aparente unidade imaginária da região sul.

Já tendo dito isso, é pertinente colocar que o texto analisado apresenta designações e expressões que corroboram com o entendimento de efeitos hostis entre a posição pró OSMP e a posição contra OSMP, atribuindo a ela uma importância antipática e reproduzindo sentidos de ultraje. A presença das diversas designações nos faz pensar se tratar de um efeito de repetição, que, por sua vez, se torna um excesso, indo ao encontro de Ernst (2009, p. 04) quando escreve que esse se apoia "na repetição de palavras ou expressões e orações”, bem como a combinação 
190 | Stella Aparecida Leite Lima e Luciana Iost Vinhas

aos significantes ultrajantes que acabam funcionando como intensificadores do seu discurso ${ }^{80}$.

Dessa maneira, elencamos recortes nos quais consideramos a presença do excesso: "entre tantas asneiras que fala dentro da universidade onde leciona" (SD02); "em um dos livros que derrama sua gonorreia ideológica socialista" (SD03); "considerando inclusive hábitos da sua gente uma aberração" (SD04); "acreditamos que o professor Tau Golin não tem gabarito para tal análise" (SD08); e as designações, historiador, velho inimigo, aquele que quer extinguir os CTG, sem escrúpulo, inveterado defensor (da cultura Cubana), crítico sem profundidade, sem caráter, intolerante, cego pela sua ideologia, pseudohistoriador, pena alugada.

Compreendemos que, ao designar, o sujeito "ao mesmo tempo, nomeia, refere e qualifica o objeto de sua referência" (GUADANINI, 2010, p. 118), isto é, a posição contra OSMP. Usando uma "designação por identificação genérica exemplar” (op. cit. p. 118), desqualifica o outro e, da mesma forma, "sua maneira de falar não só capta e prende a atenção de quem ouve como também apela para a memória" (ORLANDI, 2016, $\mathrm{s} / \mathrm{p}$ ) do leitor sobre os significantes utilizados (asneiras, gonorreia, velho inimigo, sem escrúpulo, sem caráter, intolerante). Ao mesmo tempo, os significantes evidenciam "uma relação de designação sendo estabelecida pelo uso de nomes comuns" (GUADANINI, 2010, p. 118), e nos deixam a compreensão de que, com sua carga semântica negativa, foram empregados para depreciar a posição contra OSMP.

Segundo Guadanini (2010, p. 118), "o nome comum individualiza o ser em referência no discurso, mas insere-o numa classe”. Isso nos possibilita compreender que o texto analisado, ao colocar em funcionamento as designações, individualiza a posição contra, "nega (...) a alteridade e acentua (...) a criação e a preocupação com os "inimigos"” (CASARA, 2015, p. 14).

Com efeito, o texto analisado reproduz sentidos de odiosidade e "não por acaso, a intolerância torna-se uma constante, conduzindo à repressão da diferença” (CASARA, 2015, p. 13), o que, em nossa compreensão, acaba por "estabelecer provavelmente a relevância de

${ }^{80}$ Eni Orlandi analisa o discurso de Donald Trump nessa mesma direção.

Disponível em

$<$ http://revistagalileu.globo.com/Sociedade/noticia/2016/11/pedimos-uma-

linguista-para-analisar-o-discurso-de-donald-trump.html>. Acesso em 10 de outubro de 2017. 
O funcionamento da ideologia no discurso separatista: uma análise de um texto vinculado ao movimento O Sul é o meu país | 191 saberes de uma determinada formação discursiva através da repetição" (ERNST; MUTTI, 2011). Em outras palavras, saberes provenientes da FD separatista reproduzem os sentidos "em detrimento da identificação que particulariza” (GUADANINI, 2010, p. 118).

Assim, com base na reprodução dos saberes da FD Separatista, pode ocorrer, através do processo de designação "uma espécie de (re)categorização das relações entre as palavras e o mundo vivido, com um determinado propósito do sujeito designador" (GUADANINI, 2010, p. 114), seja de descaracterizar a posição contra de modo a minimizar sua credibilidade e os sentidos que dali possam emergir.

Por conseguinte, é possível identificar que o excesso nas designações dadas pela posição pró OSMP, ao referir-se ao sujeito contra OSMP, concomitante ao uso de significantes com carga semântica negativa no texto, oscilam entre a depreciação e o desprezo, conforme pode ser observado nas designações pseudo-historiador e historiador (se de fato o é).

Essas materialidades podem constituir o que Orlandi (2016) apreendeu do discurso do presidente americano eleito no final do ano de 2016. Em entrevista à Revista Galileu, a autora refere que o discurso do candidato eleito emprega formulações "curtas e certeiras, pequenos blocos de informação de fácil apreensão que costumam terminar com uma palavra impactante ${ }^{81}$ ". Assim, as palavras "impactantes" do texto analisado se misturam com as designações e pronomes de tratamento, produzindo possíveis sentidos de desmerecimento, ou desconfiança.

Já tendo relacionado os saberes da FD separatista aos saberes xenofóbicos/fascistas, podemos entender que as designações mencionadas, junto à sequência "não conseguiu argumentos honestos", favorecem o que escreve Casara (2015, p. 13), ou seja, que "o fascis(ta)mo desconfia do conhecimento, tem ódio de quem demonstra saber algo que afronte ou se revele capaz de abalar suas crenças".

Diante das reflexões acima propostas, observamos a reprodução de saberes de uma ordem que suporta sentidos de cunho discriminatório, validando efeitos, consequentemente, violentos. Isso nos faz refletir sobre a violência e sobre o ódio presentes no discurso em questão, uma vez se aproxima do que Žižek (2014) escreve sobre a violência ideológica, aquela

\footnotetext{
${ }^{81}$ Disponivel em:

$<\underline{\text { http://revistagalileu.globo.com/Sociedade/noticia/2016/11/pedimos-uma- }}$ linguista-para-analisar-o-discurso-de-donald-trump.html>. Acesso em datas diversas.
} 
que "associa as manifestações e o excesso de ódio à não tolerância do diferente, ou seja, quando o discurso do outro não vai ao encontro aos valores preconizados pelos demais" (ŽIŽEK, 2014, apud REBS, 2017).

Observamos, mesmo que brevemente, nas reflexões propostas, como a posição pró OSMP materializa no intradiscurso (através dos significantes evidenciados) os saberes que estão disponíveis no Interdiscurso e que adquirem sentidos que "ultrapassam a mera ofensa" (REBS, 2017, p. 2520). Isso devido ao fato de a FD Separatista abranger saberes que corroboram para que sentidos de ordem fascista sejam colocados em circulação.

Encaminhamo-nos, assim, para as considerações que formulam um efeito de fechamento à presente reflexão. É importante lembrar, aqui ou em qualquer estudo em $\mathrm{AD}$, que o fim nunca é propriamente o esgotar de possibilidades. $\mathrm{O}$ estudo apenas fomenta as inquietações que envolvem o discurso separatista presente no Movimento O Sul é Meu País e poderá ser desenvolvido mais profundamente em pesquisas e análises posteriores. A possibilidade teórico-analítica da Análise de Discurso possibilita que outros caminhos pudessem ter sido e possam ainda ser percorridos; consideramos necessário refletir acerca dos sentidos discriminatórios que permeiam nossa formação social atual.

Podemos compreender como o discurso separatista do grupo tem estreita relação com os saberes tradicionalistas do Sul do país; também entendemos que os saberes do separatismo, mesmo escapando ao controle imaginário do sujeito, implicam e resgatam sentidos próprios da xenofobia e fascismo.

O texto analisado, ao pôr em questão uma posição ideológica contrária à sua, chamado, portanto, o discurso-outro de forma explícita, coloca em circulação saberes próprios da não-aceitação de pressupostos contrários à sua posição. São colocados em circulação saberes fascistas diante do que possa vir a reproduzir saberes diferentes aos seus.

Assim, a estratégia discursiva empregada no texto em questão, ressalta aquilo que os separatistas tendem a negligenciar, que seus ideais corroboram para a não-aceitação do outro, desrespeitando a alteridade própria a cada sujeito, se apresentando como "meio de subjugar e aterrorizar os seres humanos internamente" (ARENDT, 1989, p. 375). 
O funcionamento da ideologia no discurso separatista: uma análise de um texto vinculado ao movimento O Sul é o meu país $\mid 193$

\section{REFERÊNCIAS}

ARENDT, H. Origens do totalitarismo. Tradução de Roberto Raposo. São Paulo: Companhia das Letras, 1989.

BENVENISTE, É. Problemas de linguística geral I. 4.ed. Campinas: Pontes, 1995.

CASARA, R. Apresentação. In: TIBURI, M. Como conversar com um fascista. Rio de Janeiro: Editora Record, 2015.

CAZARIN, E. A. Heterogeneidade discursiva: relações e efeitos de sentido instaurados pela inserção do discurso-outro no discurso político de L. I. Lula da Silva. Ijuí: Editora da UNIJUI, 2004.

ERNST, A. G. A falta, o excesso e o estranhamento na constituição/interpretação do corpus discursivo. In: SEMINÁRIO DE ESTUDOS EM ANÁLISE DO DISCURSO, 4., 2009, Porto Alegre, RS. Anais... Porto Alegre: UFRGS, 2009. Disponível em: <http://anaisdosead.com.br/4SEAD/SIMPOSIOS/AracyErnstPer eira.pdf>. Acesso em 5 de abril de 2016.

ERNST, A. G.; MUTTI, R. M. V. O analista de discurso em formação: apontamentos à prática analítica. Educação $\mathcal{E}$ Realidade, Porto Alegre, v. 36, n. 3, p. 817-833, set./dez. 2011. Disponível em: <http://seer.ufrgs.br/index.php/educacaoerealidade/article/view/ 18486/14344>. Acesso em 25 abril de 2016.

GOLIN, T. A ideologia do gauchismo. Porto Alegre: Tchê, 1983.

GUADANINI, Sandra Magna. Designação: das categorias da língua às categorias do discurso. 216 p. Tese (doutorado) - Universidade Federal de Minas Gerais, Faculdade de Letras, 2010. Disponível em:

http://www.bibliotecadigital.ufmg.br/dspace/bitstream/handle/1 843/ALDR-86YHYW/1230d.pdf?sequence=1. Acesso em 6 de março de 2017.

HOBSBAWM, E. Era dos extremos: o breve século XX: 1914-1991.

Tradução de Marcos Santarrita. São Paulo: Companhia das Letras, 1995.

INDURSKY, F. A função enunciativa do porta-voz no discurso sobre o MST. Revista Alea, vol. 2, n. 2. Rio de Janeiro, PPG em Letras Neolatinas, UFRJ, 2000. . Estudos da linguagem: Língua e ensino. Revista Organon. Porto Alegre, v. 24, n. 48. 2010. Disponível em: 
194 | Stella Aparecida Leite Lima e Luciana Iost Vinhas

http://seer.ufrgs.br/organon/issue/view/1661/showToc. Acesso em 30 de janeiro de 2016.

- Discurso, língua e ensino: especificidades e interfaces. In: TFOUNI, L.; MONTE-SERRAT, D. M.; CHIARETTI, P. (Orgs.) Análise de Discurso e suas interfaces. São Carlos: Pedro João Editores, 2011.

MARIANI, B. S. C. Subjetividade e imaginário linguístico. Linguagem em (Disc)curso, v. 03, Tubarão, Unisul, 2003.

ORLANDI, E. P. Discurso, Imaginário Social E Conhecimento. Em Aberto, Brasília, ano 14, n.61, jan./mar. 1994.

. Interpretação: autoria, leitura e efeitos do trabalho simbólico. Petrópolis: Editora Vozes, 1996.

- Análise de Discurso: princípios \& procedimentos. 8. ed. Campinas: Pontes, 2009.

Análise de Discurso. In: ORLANDI, E.; LAGAZZIRODRIGUES, S. (Orgs.) Introdução às ciências da linguagem Discurso e textualidade. 2.ed. Campinas: Pontes, 2010.

ORLANDI, R.; VINHAS, L. I. In: FAZENDO GÊNERO 11, 11., 2017, Florianópolis, SC. Anais... Florianópolis: UFSC, 2017.

PÊCHEUX, M. Análise Automática do Discurso (AAD-69). In: GADET, Françoise; HAK, Tony. Por uma análise automática do discurso: uma introdução à obra de Michel Pêcheux. Campinas: Editora da UNICAMP, 1997.

- Semântica e discurso - uma crítica à afirmação do óbvio. Tradução de Eni Pulcinelli Orlandi. Campinas: Editora da UNICAMP, 1988.

PETRI, V. Imaginário sobre o gaúcho no discurso literário: da representação do mito em Contos Gauchescos, de João Simões Lopes Neto, à desmitificação em Porteira Fechada, de Cyro Martins. 2004. 332 p. Tese (Doutorado em Letras) - Universidade Federal do Rio Grande do Sul, Porto Alegre, 2004. Disponível em: <http://www.lume.ufrgs.br/handle/10183/5534>.

RAMIL, Vitor. A estética do frio. Conferência de Genebra. Editora Satolep livros, 2004.

REBS, R. R. O excesso no discurso de ódio dos haters. Fórum Linguístico, Florianópolis, vol. 14, número especial, p. 2512-2523, no. 2017. 
O funcionamento da ideologia no discurso separatista: uma análise de um texto vinculado ao movimento O Sul é o meu país | 195

Anexo I

www.sullivre.org/uma-resposta-ao-historiador-tau-golin/

\section{UMA RESPOSTA AO HISTORIADOR TAU GOLIN}

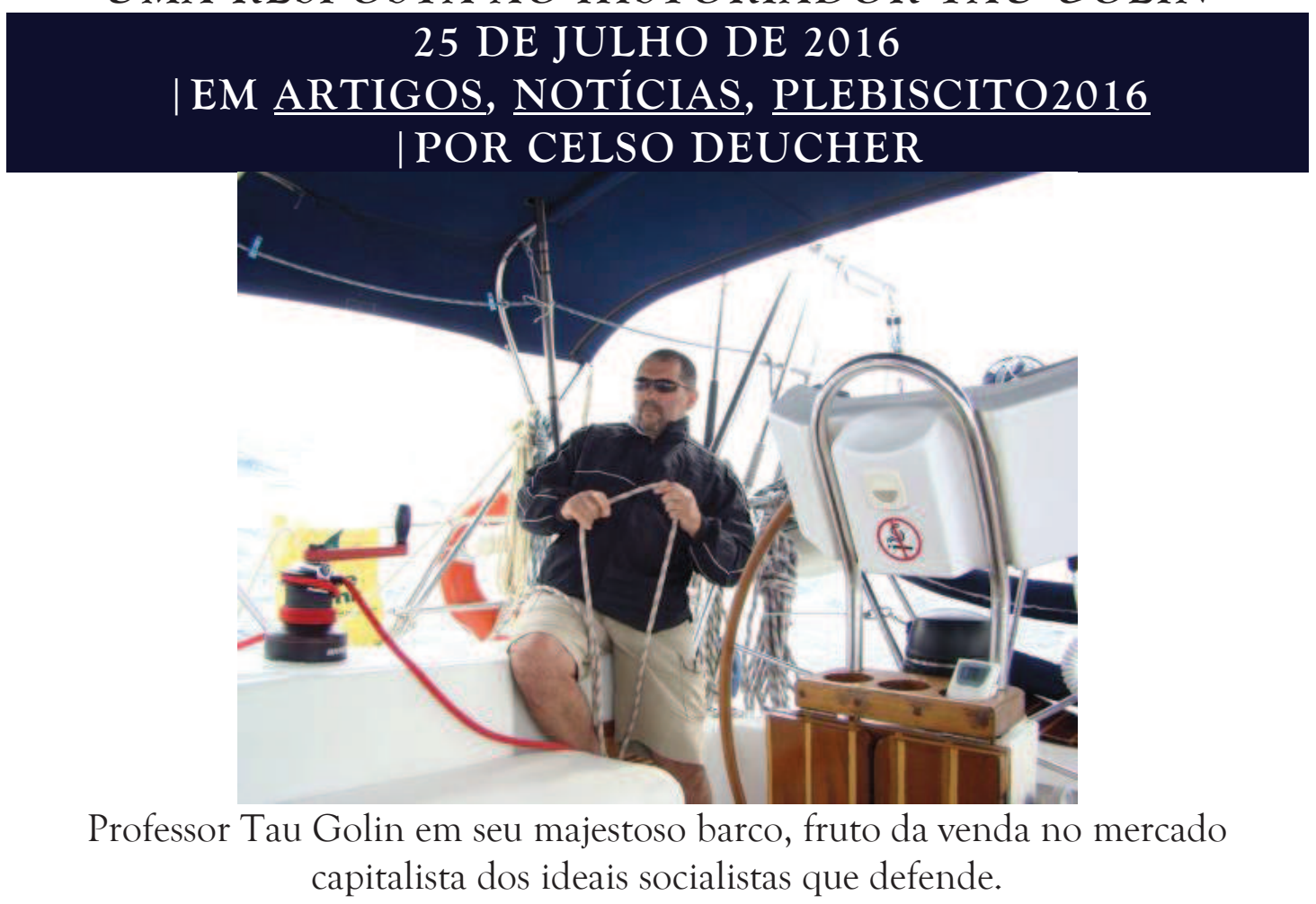

\section{Por Celso Deucher*}

O Jornal Folha de São Paulo, trouxe no dia de hoje (25/07/2016 Página A7) uma reportagem sobre o Plebiscito Consultivo que estará acontecendo em toda região Sul do Brasil no dia 2 de outubro, realizado pelo Movimento O Sul é o Meu País. Na entrevista a compatriota superintendente para o Rio Grande do Sul, Anidria Rocha, prestou esclarecimentos da consulta em abril deste ano, durante uma reunião de uma Comissão Municipal no Rio Grande do Sul e a jornalista usou estas informações para fazer a matéria. (SD01) A fala foi usada de acordo com a boa ética pela jornalista Paula Sperb, porém, ao final da reportagem, como não poderia deixar de ser (pois é costume conhecido da mídia nacional) a matéria trás uma declaração do historiador Tau Golin, velho inimigo do Povo Sulista, que não pode ficar sem resposta.

(SD02) Entre tantas asneiras que fala dentro da universidade onde leciona, Tau Golin é mais conhecido no Rio Grande do Sul como aquele que quer extinguir os CTG (Centros de Tradição Gaúcha), pois segundo ele, "trata-se de uma invenção capitalista". (SD03) Em um dos livros que derrama sua gonorreia ideológica socialista ("A ideologia do Gauchismo") 
prega sem o menor escrúpulo que a cultura riograndense é inventada e que por isso, encontra-se eivada do vicio capitalista e portanto, deveria ser simplesmente deletada para dar lugar certamente a cultura Cubana, da qual é inveterado defensor. (SD04) Desdenha em praticamente todos os seus escritos dos usos, costumes e tradições do Rio Grande, considerando inclusive os hábitos da sua gente uma aberração.

(SD05) Em relação ao independentismo Sulista sempre foi um critico sem profundidade, sem caráter e sem argumentos, limitando-se a acusações de xenofobia e racismo aos que defendem esta proposta. (SD06) [Como historiador (se de fato o é) deveria saber que quando se analisa um fenômeno social como o separatismo, há que se buscar antes de mais nada as suas causas geradoras. (SD07) $\mathrm{O}$ bom historiador não se limita a acusações, mas prova suas teses. $O$ bom historiador busca na anterioridade histórica os motivos que levam milhões de pessoas a acreditar que a independência de um determinado território é melhor que ficar a mercê de um estado central capenga, patrimonialista e pior que isso, neocolonista. O bom historiador não acusa, mas desnuda a realidade para que a sociedade a leia com profundidade e possa chegar as suas conclusões].

(SD08) É por estas e por outras que, com todo respeito à Cátedra de História da UPF (Universidade de Passo Fundo), acreditamos que o professor Tau Golin não tem gabarito para tal analise. (SD09) Intolerante e ligado a grupos fascistas no poder em Brasília até poucos dias atrás, transformou-se num dos principais críticos do direito de autodeterminação dos Sulistas, com base no medo de perder seus privilégios. (SD10) Como "historiador", esquece criminosamente Golin das origens do separatismo Sulista, que teve seu primeiro embate nas Missões do Guairá, seguiu o curso da história nos Sete Povos das Missões, mais tarde na Revolução Farroupilha, na Revolução Federalista, na Guerra do Contestado e em tantas outras revoluções gestadas no Sul. Em sua esmagadora maioria, revoluções que nasceram para lutar contra a falta de auto-governo dos Sulistas.

(SD11) Como todo historiador, pena alugada de Brasília, Golin odeia negros e índios, por isso não aceita nossa anterioridade missioneira, muito menos que entre nós estejam lutando lado a lado cidadãos de origem africana que vencem na vida pelas suas capacidades e não pelas cotas discriminadoras impostas pelo poder central. (SD12) Afinal, para Golin, "negro bom", tem que ter a marca na testa do seu partido e da sua ideologia. (SD13) Na sua analise Tau Golin destitui negros e índios do 
O funcionamento da ideologia no discurso separatista: uma análise de um texto vinculado ao movimento O Sul é o meu país $\mid 197$ seu direito de serem sujeitos da história, relegando a eles o que o Brasil sempre fez, o papel de "coisa".

(SD14) Nós os separatistas, repudiamos com veemência tais argumentos, ideias e ideologias. $\mathrm{O}$ Sr. Golin não tem o direito de tratar nossa gente desta forma. (SD15) Somos Povo e Nação cuja unidade vem sendo forjada pela nossa diversidade e ninguém vai nos destituir do nosso irrenunciável direito de sermos sujeitos do direito de autodeterminação.

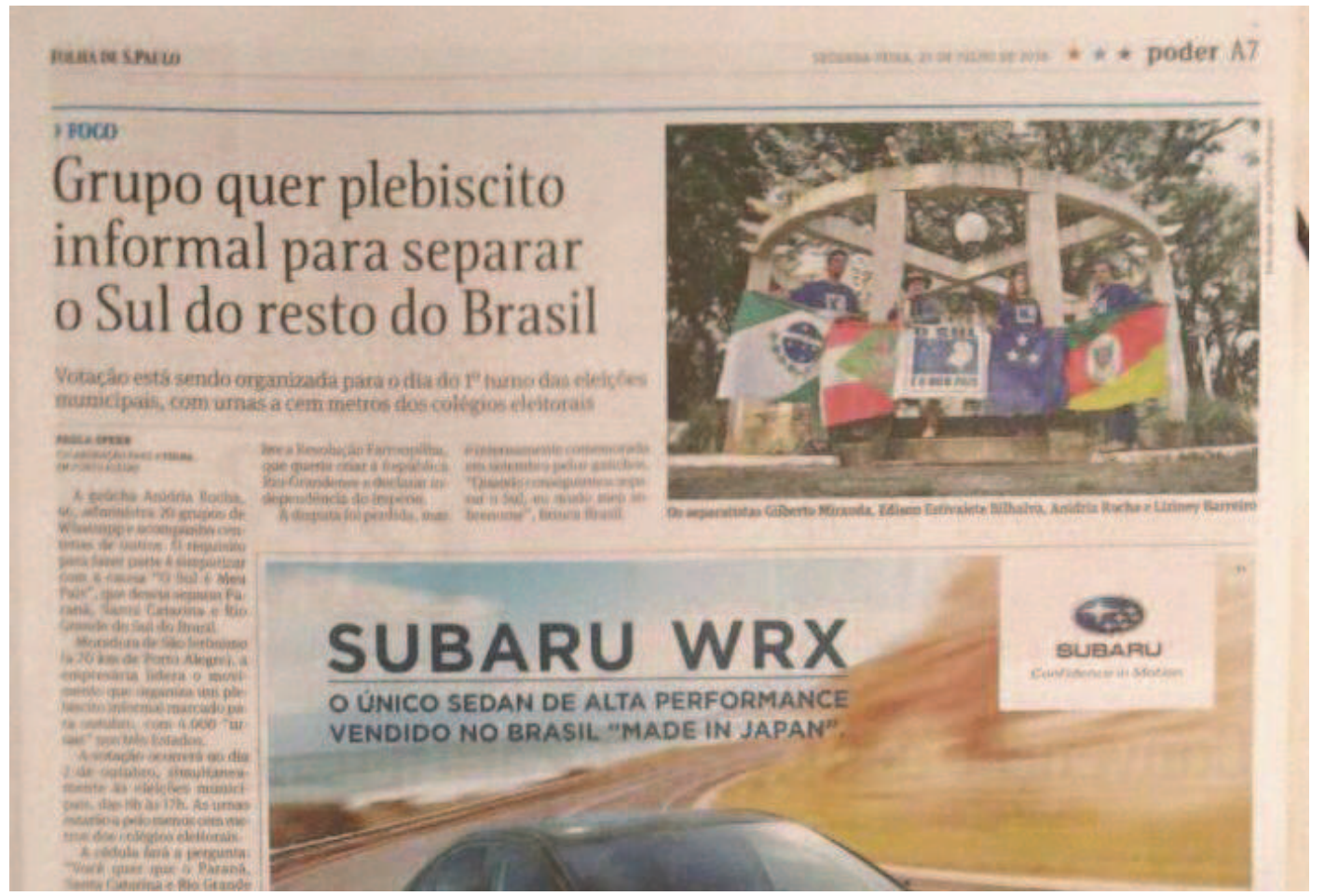

Parte da Reportagem da Folha de São Paulo, edição de 25/07/2016.

(SD16) Resta-nos ainda repudiar com todas as nossas forças as afirmações xenofóbicas do Professor Golin, quando deixou claro a reportagem da Folha seu ódio aos imigrantes europeus que chegaram ao Sul do Brasil. (SD17) Ao fazer tais afirmações o pseudo historiador coloca-se ao lado do malfadado Mussolini, quando afirmava que apenas o Estado tudo pode e que a Nação tem que estar subjugada a ele. (SD18) Portanto, sua posição ideológica está exatamente onde deveria estar, ou seja, junto com os bandidos que assaltaram o Estado Brasileiro e que aos poucos estão sendo presos pela Operação Lava Jato.

(SD19) Pelos motivos apontados acima, Tau Golin, cego pela sua ideologia, não conseguiu argumentos honestos para combater o independentismo Sulista, que nada mais quer que refazer o papel do 
estado em nossa região. (SD20) Uma pena, pois mais uma vez perdeu a oportunidade de apresentar argumentos reais a favor do Brasil unido.

(SD21) Nós os independentistas continuamos a espera de argumentos que derrubem nossas teses. (SD22) Queremos que o Sr. Golin nos explique por que nos últimos cinco anos (2011-2015), Brasília arrecadou no Sul, segundo o Portal da Transparência, R\$ 668.808.587.185,00 (quase 700 Bilhões) em impostos e voltaram para nossas cidades e estados, depois de quase implorarmos, a miséria de $\mathrm{R} \$$ 153.320.315.743,00. (SD23) A união simplesmente roubou dos Sulistas R \$ 515.488.271.441,00. Em outras palavras, Brasília deixou o Sul mais pobre em mais de $\mathrm{R} \$ 515$ bilhões em apenas cinco anos.

(SD24) Qual a resposta para este verdadeiro neocolonialismo interno? Por que o Sr. Golin vem com este covarde pseudo-argumento de xenofobia, em vez de ir a fundo e buscar as origens de tal descontentamento? (SD25) A resposta é clara, límpida e transparente, o Sr. Golin defende as oligarquias políticas, donas do Poder Central (incluindo-se algumas do Sul) e os seus privilégios de pena alugada de Brasília.

*Celso Deucher é um dos fundadores do Movimento O Sul é o Meu País e seu expresidente, atual Secretário geral do Grupo de Estudos Sul Livre (Gesul).

Recebido em: 17/11/2018

Aceito em: 26/11/2018 